\title{
Administrative and Legal Support Challenges of Environmental Safety Under Globalization
}

\author{
Volodymyr Haraschuk ${ }^{1}$, Yana Zelinska², Viktoriia Spasenko ${ }^{3}$, \\ Oleksandra Shynkaruk ${ }^{4}$
}

\begin{abstract}
The article investigates the underlying challenges of administrative and legal support of environmental safety under globalization. The current globalization conditions and factors affecting the transition of environmental safety from local to a global level, which is due to globalization processes in the world and a number of global anthropogenic challenges, are analyzed. The emphasis is focused on the impact of globalization on the adoption of international treaties in the field of environmental safety. The importance of administrative and legal environmental safety at the state level for the implementation of the executed international treaties is substantiated. The obsolescence and underperformance of the current state of administrative and legal support of environmental safety in Ukraine is grounded, the necessity for its optimization is proved, the weaknesses are highlighted and the need for introducing a number of improvement directions, including propaganda of a careful attitude to the environment, is substantiated; regulatory support for the effective distribution of functions and viable mechanism for management of central and local executive authorities, local government institutions on the formation and implementation of state policy components in the field of climate change in accordance with their competence; regulatory actions of joint events and cooperation of domestic government bodies in the area of environmental safety with similar bodies of neighboring countries; implementation ensuring of the provisions of the Association Agreement between Ukraine and the European Union, the European Atomic Energy Community and their member states related to climate change; ensuring the fulfillment of Ukraine's obligations regarding reporting on international agreements in the field of climate change, etc.
\end{abstract}

Keywords: globalization, environmental safety, state environmental policy, legal support of environmental safety, administrative and legal support for environmental safety of Ukraine, international legal support for environmental safety

\section{Introduction}

Natural resource conservation and sustainable development of the environment today are the high-priority task of the world community. A number of conventions have been adopted on its implementation by the international community (a system of governmental and non-governmental international organizations), imposing the duty of environmental care, which is the only possible humans' habitat as a biological species.

\footnotetext{
${ }^{1}$ Doctor of Law, head of the Department of Administrative Law of Yaroslav Mudryi National Law University.

2Ph.D. in Law, assistant professor of the Department of Administrative Law of Yaroslav Mudryi National Law University.

${ }^{3}$ Ph.D. in Law, assistant professor of the Department of Administrative Law of Yaroslav Mudryi National Law University.

${ }^{4}$ Ph.D. in Law, associate professor of the Department of International Relations and Social Sciences of the National University of Life and Environmental Sciences of Ukraine.
} 
These primarily include the Montreal Protocol (The Montreal Protocol on Substances that Deplete the Ozone Layer), the Aarhus Convention, the Framework Convention, the Kyoto Protocol, the Paris Agreement and the like. All of them are aimed at encouraging the state to take a set of necessary political and legal actions to maintain the ecological balance. During globalization of world development, environmental issues enter into the picture and run far beyond the borders of the state, because no state alone can overcome such challenges as increasing $\mathrm{CO}_{2}$ emissions, global warming, formation of ozone holes, etc. Unlike the state, the environment is not divided into administrative borders, and therefore the harm caused by one country will certainly lead to a general deterioration of the environmental situation in the region. However, this does not reduce the role of specific states, their governments relating to the obligation to ensure environmental safety at the local level. By signing an international treaty, the state assumes the responsibility of consistently fulfilling it by implementing its own state policy to ensure environmental safety, it implements primarily administrative-legal instruments. Taking into consideration the current state of environmental safety of Ukraine, the existing administrative and legal measures of environmental safety should be investigated to understand the grounds for their relative inefficiency or poor efficiency.

\section{Environmental protection is a growing global issue.}

Today, the world faces significant challenges on the deterioration of the Earth's ecology, on which the state of the natural ecosystem, life and health of current and future generations depend. Ozone holes, global warming, air pollution and hazardous atmospheric emissions have prompted the world community to recognize the harmful effects of human impact, especially during the last century in the era of global industrialization and wasteful use of natural resources. The present-day globalizing world is characterized by rapid population growth, increase in imbalances in socio-economic development and resource's allocation between rich and poor countries, and an increase in anthropogenic pressure on the environment. All of these lead to an aggravation of contradictions in the "man-nature" system, and environmental issues have been gradually becoming a source of global relations complication [1].

The environment today takes on the role of the only possible human environment, the deterioration of which will certainly account for an impairment in the quality of life of every living creature. Scientific and technological progress and industrialization vividly have been carrying out over the past century, and now continues to increase the use of irreplaceable natural resources, primarily for energy production. This, in turn, entails significant emissions into the atmosphere, not only polluting the environment but also causing global warming, the consequences of which may be irreversible. Generally, all these processes occur in specific countries, which are responsible for their own $\mathrm{CO}_{2}$ emissions into the atmosphere. However, it should be noted that environmental harm goes beyond the boundaries of a specific country and affects the general global environmental situation. For example, industry development in China over the past 40 years has a significant impact on global environmental safety. So, it is quite obvious that the challenge of ensuring environmental safety goes beyond the administrative borders of specific countries, and therefore this problem is applied today to the entire 
international community and is assuming global nature. It is quite obvious that the efforts of the entire world community in the field of environmental preservation, reduction of emissions into the atmosphere are of extreme necessity in modern conditions.

\section{Globalization process is the key focus of human development.}

There is a clear trend towards the politics replacement from the regulatory scope of social processes now. The reins of political power are replaced by financial ones, which forces entire countries to carry out certain transformations, to implement certain technical and economic innovations, to train their own personnel in a different way, and even to form their own power structures differently [2]. It is worth noting that this trend is only gaining momentum, and all political, economic, social and cultural processes undergo integration and unification. The globalization process is objective and is determined by the development of transport, international traffic, communication media and the acceleration of commodity relations. Encompassing all spheres of society, it indicates its systematic nature. It can be said that the globalization today provides a closer and more permanent connection between states, which in turn makes them more dependent on each other. However, all this gives rise to a commonness of problems of economic, political, and primarily of environmental nature.

The globalization process can be defined as closer economic integration of the world as a result of liberalization and a further increase in the volume and diversity of international trade in goods and services, a drop of transport prices, an increase in the intensity of international capital stock penetration, a huge increase in a global workforce and accelerated technological expansion on a global scale, in particular, of contacts [3]. Indeed, the economic component is the driving force of the globalization and become the leverage over the states to transformations that can be both useful in terms of respect for human rights and vice versa. So, if globalization in itself does not violate human rights, however, it can be said about a possible negative impact on the enforcement of the common human rights throughout the world. These issues include human rights obligations from private actors, such as transnational enterprises, reinforced by the fact that national governments have more limited control over socio-economic processes due to economic and political globalization. Another example concerns the primacy that government decisions on human rights issues should have, which are in question, especially when the economic policies of governments depend on market fluctuations and the actions of foreign investors, as well as the settlement of trade disputes. These include the rights to equality and dignity and non-discrimination, for example, due to bad health and safety conditions for workers in developing countries [4].

Thus it may be said that the globalization process is an ambiguous phenomenon because there are a number of risks that may arise with the enforcement of common human rights. However, if financial influence leverage on globalization can be discussed in view of the fact that it is beneficial for those countries that are economically developed, then speaking about the challenges to environmental safety posed by the effects of anthropogenic environmental impact, there can be no doubt about the globalization necessity. To stop the process of pollution, the depletion of natural resources and their 
components, the stabilization of global warming is possible only under the condition of stable and sustainable cooperation of states within the framework of international governmental and non-governmental organizations. In this case, environmental safety is a global phenomenon, and its provision is part of the common interests of all the peoples and nations.

Mitigation the human intervention effects has become the task of international legal support of environmental safety at the global level. The United Nations today is a key platform for discussion and decision-making on global environmental challenges caused primarily by anthropogenic impact. As a result of its activities, a number of international agreements have been adopted aimed at reducing carbon dioxide emissions into the atmosphere, environmental information disseminating, stimulation of the transition to renewable fuels, reducing the share of fossil energy sources, etc. The United Nations Environment Programme (UNEP) also plays a prominent role, which carries out research, assesses the state of the environment and makes recommendations for the conservation of natural resources and pool all countries' efforts to develop common policies and solutions to address risks and to settle the specific environmental challenges. As of this date, the UN has adopted a number of international legal acts in the field of environmental safety. These include the Aarhus Convention, the Framework Convention on Climate Change, the Kyoto Protocol to the Framework Concept, the Paris Agreement. The primary objective of these acts is to reduce $\mathrm{CO}_{2}$ emissions into the atmosphere, reduce the share of fossil energy sources and shift to green energy.

It is worth mentioning that environmental safety issues have begun globalization prior to the adoption of the aforementioned international acts. Thus, environmental safety was the subject of a UN General Assembly resolution of 1968, which emphasized the "ongoing and rapid deterioration of the environment" and the harmful "impact on human living conditions, their physical, mental and social well-being, their dignity and the exercise of fundamental human rights both in developing countries and in developed countries." The resolution defined "the relationship of a man and his environment is undergoing profound alterations in the development of modern science and technology" [5]. An important step in the international legal regulation of international environmental safety was the Stockholm UN Conference on the Human Environment in 1972, which founded the UNEP [6], as well as the adopted Environmental Action Plan and the Stockholm Declaration on Environment.

The strategy contains recommendations on what actions the states should take to protect the environment. They include relatively-distinct groups of recommendations in five areas: population planning and management; environmental aspects of natural resource management; identification and control of pollutant substances of international concern; study and strengthening of the educational, informational, social and cultural aspects of environmental issues; integration of development and environment, etc.

In the realities of the modern system of state-organized social order, sovereign countries play a critical role in reorienting the "man-nature" relationship towards sustainable development. It is at the state level with the help of a range of mechanisms of the legal impact, the abstract process of greening grows into a real character and implementation. Government bodies, implementing their own environmental policy by administrative and legal measures, ensure the execution of international treaties. Undertaking managerial 
and administrative activities, the state does not only adhere to international legal agreements but also takes measures aimed at environmental safety, which is an intrinsic part of the state homeland security. And therefore, the state of the planet's ecosystem largely depends on the success of the implementation of programs and strategies of environmental policies conducted at the national level by each country.

\section{Place of administrative and legal support in the field of environmental safety.}

Traditionally, the tasks of administrative and legal support are considered a set of actions of public authorities aimed at implementing public policy in the relevant field. These tasks can conditionally be divided into the following groups: 1) economic; 2) regulatory; 3) social; 4) managerial [7]. Administrative and legal support in the administrative law theory is considered an integral part of public administration, its legal form. The forms and methods of administrative support are customarily distinguished. The forms usually include: the promulgation of legal acts; the formation of administrative and legal contracts; the commitment of legally binding actions (state registration, certification, licensing, granting of permits); the publication of other official documents; monitoring and supervision; an official investigation. Methods of administrative and legal support can be legal and unlawful (managerial, organizational) [8].

Administrative and legal support can be considered in a broad and narrow sense. In a broad sense, "administrative and legal support" is the ordering of social relations by state-authorized bodies, their legal consolidation with the help of legal canons, protection, implementation and development. A narrow definition of the concept of "administrative and legal support" will vary depending on the kind of public relations being in question.

Administrative scientists disclose the contents of administrative legal support through the prism of regulatory procedures using the provisions of administrative law of social relations arising for and during the enforcement of human and civil rights and freedoms [9]; via a set of administrative and legal actions and means aimed at creating appropriate conditions for the effective implementation, defense, protection and restoration of the violated rights and freedoms [10] or are considered as the implementation by the state with the help of legal norms, regulations and a combination of means to regulate the social relations, their legal recognition, protection, implementation and development [11]. Accepting the statement that there are static and dynamic aspects in the structure of legal support, it must be admitted that the content of administrative and legal support for environmental safety in Ukraine, on the one hand, covers a system of administrative and legal safeguards for the application of public and legal, environmental, organizational, technical and other measures in the field of environmental safety, in particular, institutional and administrative and legal means of influence in the field of preventing the environmental deterioration of the environmental situation and hazard outbreak to people health, repression of environmental offences in this area; and, on the other hand, their implementation as a targeted impact of public authorities and other entities on public relations in the field of environmental safety. These activities are coordinated and implemented in practice by the Ministry of Energy and Environmental Protection 
through a system of environmental monitoring and supervision actions, the state environmental monitoring system [12].

Administrative and legal support of environmental safety in Ukraine consists in creating a stable foundation for maintaining the protection state of the vital interests of a person, society, country and environment through a system of regulatory administrative and legal support, legal and procedural guarantees of environmental safety in Ukraine.

That is, the administrative and legal support of environmental safety in Ukraine is a combination of administrative and legal safeguards and activity-based means of supporting the state of protection of the vital interests of a person, society, country and environment, whereby the common right to a healthy and safe environment is guaranteed and the necessary conditions for defense exist. What is important to notice herein is that that the task of environmental safety as a type of national security is closely intertwined with the tasks of global environmental safety, and it may be said that the administrative and legal support for the environmental safety of Ukraine is aimed primarily at fulfilling obligations undertaken by signing agreements. The basis of administrative and legal support of environmental safety is the desire to the enforcement of the law, public order, sound management and protection of natural resources, respect for environmental human rights, and the like. This is the common goal of international environmental and national safety.

The substantive legal framework for the administrative and legal support of environmental safety in Ukraine are: the Code of Ukraine on Administrative Offenses, the Water Code of Ukraine, the Subsoil Code of Ukraine, the Land Code of Ukraine, the Forest Code of Ukraine; the laws of Ukraine: "On National Security", "On the National Police of Ukraine”, “On Environmental Protection”, "On High-Risk Objects of 2001”, "On the Use of Nuclear Energy and Radiation Safety", "On Providing Sanitary and Epidemic Safety of the Population", “On Civil Service”. The concept of implementing state policy in the field of climate change for the period up to 2030 and in many other regulatory legal acts.

However, today Ukrainian legislation requires groundbreaking changes in the direction of human-centrism and transparency of administrative and regulatory activities in the field of environmental safety. Namely, - Today, the legislation provides for the subordination of supervising bodies to the executive one, that virtually eliminates the possibility of preventing abusive practice by the latter. It can be argued by experience that the operation of the state body for nature (environment) preservation as part of government structures is less than effective, and the dependence of its regional divisions on the local executive authorities practically keep a check on their activities; - despite the legislatively secured right of citizens to receive a real opportunity to exercise control over the actions of government agencies with the help of independent judicial bodies, to date, a clear definition of the competence of the court in this matter has not been regulated.

One of the key issues of the current stage of administrative and legal support of environmental relations is the problems associated with the environmental monitoring system. Assessment of the current condition of the environmental monitoring system indicates the issues of inadequate organization and monitoring of environmental pollution at industrial and energy enterprises. In spite of the fact that continuous monitoring of the environment at enterprises representing an increased environmental 
hazard is mandatory in the European Union, it has gradually been reduced in recent years in our country. Besides, the owners of industrial enterprises are not interested in environmental monitoring and compensation for losses incurred as a result of environmental pollution. Under modern conditions, a significant number of industrial enterprises that consume large amounts of natural resources and pollute the environment is in operation without obligatory strategic environmental assessment, that would make it possible to adequately assess the environmental damage.

Due to the lack of recognized formats for maintaining the results of environmental observations in departmental databases, the possibilities of their use in a unified monitoring system are significantly hampered. Extremely insufficient level of use of modern technologies of geographic information systems and remote sounding of the Earth to obtain and to submit environmental information significantly complicates the processing and analysis.

Among the urgent problems of the operating of the environmental monitoring system, it can be noted the lack of effective management and the insufficient level of coordination during the monitoring works both at the regional and state levels, that should be provided by specially authorized executive bodies in the field of rational use of natural resources, environmental protection and environmental safety [13].

The last decision of the Government of Ukraine to merge the Ministry of Energy and Coal Industry of Ukraine and the Ministry of Ecology and Natural Resources into the Ministry of Energy and Environmental Protection is unclear [14], taking into account the diversity and inconsistency of their tasks. So, if the Ministry of Ecology and Natural Resources is aimed at protecting the environment, then the Ministry of Energy and Coal Industry, on the contrary, organizes the extraction of natural resources. In our opinion, by mixing different ministries that controlled each other, the system of checks and balances can weaken, that will rather lead to a weakening of the environmental safety of Ukraine.

The lack of efficiency and clarity in the division of powers within the executive branch requires special attention. Obviously, there are fields where re-division (forestry, household waste) or improvement (for example, the introduction of water basin management should be supported by an appropriate re-division of powers at the regional/district/basin level) of powers is required. In addition, a radical reform of the distribution of powers on certain issues is necessary for the effective implementation of the relevant functions by the state in general (for example, the formation and implementation of state environmental policy, environmental control, environmental monitoring, data collection and reporting, and preparation of information for decisionmaking). There are areas where the effectiveness of distributed powers directly depends on the level of cooperation/coordination (climate change) [15].

Despite the existence of a number of international treaties on environmental cooperation between domestic public authorities and environmental public authorities of foreign countries (for example, the Agreement between the Ministry of Ecology and Natural Resources of Ukraine and the Ministry of Environmental Protection and Regional Development of the Republic of Latvia on Cooperation in the Field of Environmental Protection) their declarative nature should be noted. Recent environmental challenges in Ukraine, namely the forest fire in Chernobyl and the fire in the Zhytomyr region that 
made Kiev the most polluted city in the world [16] showed a lack of two-way communication to assist in firefighting. Ukrainian fire equipment was not able to quickly put out fire in the woods.

The absence of the automated system for collection, analysis and processing of information on the state of environmental objects [17] is another extremely important element for an effective response to anthropogenic challenges regarding natural resources. The presence of this system is critically necessary for the permanent monitoring of the environmental condition and the quick response, the introduction of environmental-friendly measures will make a significant contribution to ensuring sustainable development of the environment.

The prevailing method of coercion before persuasion, that is, preventing the commission of administrative offences in the use and protection of natural resources, occurs primarily by fines increasing. So, in accordance with the latest changes to environmental legislation, namely: the Law of Ukraine "On Amending of Certain Legislative Acts of Ukraine regarding the Improvement of the Legislation on Amber and Other Mineral Extraction" dated 19.12.2019, significantly increased the amount of the administrative fine, for example, for "failure to comply with a requirement of mining extraction." However, in our opinion, attention should be focused mainly on the promotion of environmental culture and consciousness among citizens, to educate them on zero tolerance for harming nature. This should be a system of administrative and legal measures aimed at introducing special social videos on television channels and other mass media, state educational programs and events, conferences, etc.

So, the administrative and legal support of environmental safety, which consists primarily in the system of power-management decisions, monitor and supervision, bringing to legal responsibility for environmental offences, as of this date, should be recognized as ineffective and outdated, which requires the implementation of a number of modern measures among which the key ones are the implementation and ensuring a clear division of powers within the executive branch, the introduction of an automated system for collection, analysis and processing of information on the state of environmental objects, the signing of departmental agreements and the introduction of effective mechanisms for cooperation with environmental authorities of the near abroad, etc.

\section{Principal lines of the development of administrative and environmental safety in the context of globalization}

In the context of globalization, the global society requires the effectiveness and coherence of the implementation of administrative and legal measures to ensure environmental safety as uniform effective mechanisms for the implementation of environmental policy both in the state and the world.

The level increase of administrative and legal support for environmental safety in Ukraine should take place on the basis of the priority of introducing the environmental education of citizens, popularization of a caring attitude towards the environment; regulatory support for the effective distribution of functions and a viable mechanism for coordination of central and local executive authorities, local self-governing bodies on the formation and implementation of components of state policy in the field of climate 
change in accordance with their competence; legal regulation of joint events and cooperation of domestic government bodies in the field of environmental safety with similar bodies of neighbouring countries; ensuring provisions enforcement of the Association Agreement between Ukraine and the European Union, the European Atomic Energy Community and their member states related to climate change; ensuring obligations compliance of Ukraine regarding reporting on international agreements in the field of climate change; identification and implementation of viable mechanisms for the integration of climate change policy components in regional development strategies and action plans for their implementation, taking into account the development priorities of the districts of the corresponding region, as well as cities, towns and villages; ensuring equal access of citizens to information on all aspects of solving the problem of climate change and low-carbon development of the state, including educational and awarenessbuilding work; ensuring public participation in managerial decision-making in the field of climate change; assistance in the creation and continuous updating of models for forecasting greenhouse gas emissions according to different scenarios for the economy development of the state and its individual sectors; facilitating assessments on a regular basis of actual expected climate changes and their consequences, including regional distribution, identifying risks and exposure to climate change at the level of territorial communities, sectors of the economy.

\section{Conclusions}

Administrative and legal support of environmental safety of Ukraine should be understood as a system of managerial, administrative, environmental, organizational, technical and other actions in the field of environmental safety, institutional administrative and legal means of influence in the field of preventing the environmental degradation and danger to human health, and the cessation of environmental violations and bringing perpetrators to legal responsibility.

The need to make changes to the current system of administrative and legal support for environmental safety today in the context of globalization is dictated by the rapid change in climatic conditions as a result of anthropogenic impact, the absence of administrative boundaries in the ecology, and the understanding of the direct cause-effect relationship between the actions of each individual state and general climate change. Reducing greenhouse gas emissions into the atmosphere is possible only with the direct and steady observance and implementation of international legal treaties on climate change by each signatory state, through the application by government authorities of regulatory, administrative and legal measures as a part of the implementation of the state environmental policy. Only effective, not imitative administrative and legal measures to ensure environmental safety will be able to influence the global ecology. Today, the obsolescence and underperformance of the current administrative and legal measures to ensure environmental safety, which makes the implementation of international environmental agreements practically ineffective, is noted in Ukraine.

The current state of administrative and legal support of environmental safety in Ukraine indicates the need for its optimization and updating. The principal directions of improving the administrative and legal support of environmental safety are the 
implementation of a state program of environmental culture for citizens; increased fines for environmental offences; regulation of coordination and functional activities between central and local agencies of state power, local self-government bodies in matters of implementation of state environmental policy; legal regulation of joint events and cooperation of domestic government bodies in the field of environmental safety with similar bodies of neighbouring countries; identification and implementation of viable mechanisms for the integration of climate change policy components in regional development strategies and action plans for their implementation, taking into account the development priorities of the districts of the corresponding region, as well as cities, towns and villages; ensuring equal access of citizens to information on all aspects of solving the problem of climate change and low-carbon development of the state, including educational and awareness-raising work; ensuring public participation in managerial decision-making in the field of climate change; assistance in the creation and continuous updating of models for forecasting greenhouse gas emissions according to different scenarios for the development of the state and its individual sectors economy

\section{References}

1. Fedun, O. V. (2012) International relations greening in the context of sustainable development. Bulletin of the University of Lviv. International Relations Series. - Lviv: I. Franko NUL. - No. 30. P. 78-86.

2. Naumkina, S., Tkachuk. Yu. (2005) Globalization: tendencies of integration, universalization and polarization of the modern world // Political management. - 2005. - No. 6. P. 121 - 128.

3. Shalmali, H. (2007) "Globalization" in development in practice, vol. 17 no. 3/5, pp. 523-531 URL: www.jstor.org/stable/25548249

4. Compass: Manual for Human Rights Education with Young People Council of Europe. (2017) Strasbourg Cedex. https://www.coe.int/uk/web/compass/globalisation

5. UNGA Resolution (1968) "Problems of the Human Environment" No 2398 (XXIII) URL: http://www.un.org/ru/documents/ods.asp?m=A/RES/2398(XXIII)

6. UNGA Resolution (1972) "Institutional and Financial Arrangements for International Environmental Cooperation" No 2997 (XXVII) URL: http://daccess-dds-ny.un.org/

7. Tatsyshyn, I. B. (2009) Administrative and legal support of information relations in the field of advertising: extended abstract of the thesis... Cand. of Law: 12.00.07. - Lviv. - 18 p.

8. Filippov, A. V. (2010) Administrative and Legal Support for Civil Aviation Security in Ukraine: extended abstract of the thesis... Cand. of Law: 12.00.07. - Irpin. - 19 p.

9. Iierusalimova, I. O. (2006) Mechanism of administrative and legal support of human and citizen's rights and freedoms: thesis... Cand. of Law: 12.00.07. - K. -205 p.

10. Korzh-Ikaeva, T. H. (2008) Administrative and legal support of the rights and freedoms of minors: thesis... Cand. of Law: 12.00.07. - K. - 219 p.

11. Rymarchuk, H. S. (2013) Administrative and legal support of intellectual property rights: extended abstract of the thesis... Cand. of Law: spec. 12.00.07 "Administrative Law and Procedure; Finance Law; Information Law". - Lviv. - 18 p.

12. Environmental Monitoring (2017) Ministry of Energy and Environment of Ukraine URL: https://menr.gov.ua/content/ekologichniy-monitoring-dovkillya.html 1

3. Dzhyhyrej, V.S. (2002), Ekolohiia ta okhorona navkolyshn'oho pryrodnoho seredovyscha [Ecology and environmental protection], KOO, Kyiv, Ukraine

14. Resolution of the Cabinet of Ministers of Ukraine of September 18, 2019 No. 847 Regulations of the Ministry of Energy and the Environment URL: http://mpe.kmu.gov.ua/minugol/control/publish/article?art id $=245402199$ 
15. Andrusevich, N., Holubovska-Onisimova, H. (2018) Good Environmental Governance in Ukraine: Compliance with European Principles. Analytical document. Kyiv, VEHO MAMA-86, URL: https://www.rac.org.ua/uploads/content/463/files/analytics2.pdf

16. Air quality around the world Real-time air quality report and air pollution forecast (2020) data from site URL: https://www.iqair.com/ru/ukraine/kyiv-city

17. Varlamov, E.M. Technical and metrological support for water monitoring, taking into account the requirements of the EU Directives. URL: https://www.unece.org/ 